\title{
INVESTIGATING THE RELATIONSHIPS AMONG ERP SYSTEMS SUCCESS DIMENSIONS: A STRUCTURAL EQUATION MODEL
}

\author{
Princely Ifinedo, Cape Breton University, Canada, pifinedo@gmail.com
}

\begin{abstract}
The objective of this paper is to empirically test the relationships among the dimensions in an extended Enterprise Resource Planning (ERP) systems success measurement framework. To test the relationships, a conceptualized model highlighting the paths among the constructs or dimensions is formulated. A 41-item questionnaire was developed from the relevant literature and distributed to 470 firms in two Northern European countries. Sixty two (62) participants from 44 diverse, industrial organizations returned their questionnaires. Using the structural equation modeling technique to examine the hypothesized paths or relationships, the analysis confirmed four of the five hypotheses developed. Insights from this research will be beneficial for information systems (IS) success evaluations researchers and may serve as a base for future investigations.
\end{abstract}

Keywords: ERP systems, ERP success, IS Success, Evaluation, Interrelationships, Structural Equation

\section{INTRODUCTION}

Enterprise Resource Planning (ERP) systems are configurable, off-the-shelf packaged software that integrates organizational data resources into a unified system. Organizations adopt them to increase productivity, reduce costs, and improve customer service, among others $[9,10,18]$. AMR Research [2] reports that the ERP market worldwide is to grow from US $\$ 47.8$ billion in 2004 to US $\$ 64.8$ billion by 2009 , which gives an indication of the popularity of the software in modern organizations. It comes as no surprise, then, that much of the extant literature on ERP deals with issues relating to their implementations $[5,11,13,15]$. Few have investigated ERP systems success issues in general (e.g., $[12,14,26]$ ), and none has examined the relationships among ERP systems success dimensions. For the purposes of this study, ERP systems success (synonymous with ERP success) refers to the use of such systems to enhance organizational effectiveness $[12,14]$, which is different from the technical implementation success of such systems wherein measurement indicators such as cost overruns, project management metrics, and time estimates are the main concerns [21].

This study is motivated, in part, by the lack of research in the information systems (IS) field dealing with the success of ERP systems beyond the implementation phases. Additionally, it is inspired by the inherent need to increase our understanding of the relationships among the relevant dimensions of ERP success. In their influential work, DeLone and McLean [10, p.88] concluded "By studying the interactions along these components of the model [dimensions of IS success], as well as the components themselves, a clearer picture emerges as to what constitutes information systems success." Moreover, other researchers (e.g. [1] have studied the interrelations among critical success factors in the early stages of ERP implementations; this study complements such efforts. Importantly, insights from this research may benefit both ERP practitioners and IS success evaluations researchers.

\section{BACKGROUND}

Over the past three decades, evaluating the value and success of IT systems for organizations has been a recurring issue $[10,12,17]$, and various assessment approaches have surfaced [see 15]. Thus, perhaps it was the plethora of IS success assessment approaches that led Keen [17] to seek clarification of the "dependent variable." In response, DeLone and McLean (D\&M) [10] developed an integrated, multidimensional, and inter-related IS success model (Figure 1) that has become the most dominant framework for assessing IT systems success at the micro level $[15,16]$.

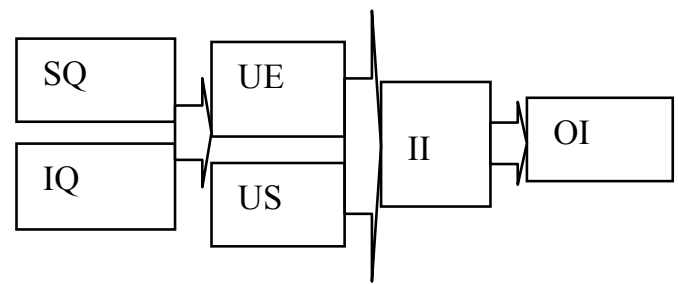

Figure 1. DeLone and McLean (1992) IS Success Evaluation Model

(Note: The acronyms are explained in the text) 
Drawing from the work of DeLone and McLean [10], Gable and colleagues [12, 26] developed an additive ERP systems success measurement model that redefines the dimensions in the original D\&M IS success model (see Figure 2). It is important to point out that ERP systems are different from other IT systems [8, 9, 18, 27] because ERP implementation includes technological, operational, managerial, strategic, and organizational related components [9, 27]. As a consequence, success measurement models used for other typical IT systems' evaluation may not be adequate for ERP systems [12, 15, 27]. Thus, it is illuminating when attention is paid to ERP systems particularly, rather than just lumping them together with other IT systems. Indeed, DeLone and McLean [10] stress that researchers should take into account the specific characteristics of the IT system under investigation when evaluating its success. Given that ERP systems are a different class of IT systems, it is therefore vitally important for a specialized success measurement framework or model to be used when evaluating or measuring the success of such systems.
Gable et al. [12] eliminated (through multi-stage data collection and statistical analysis) the Use (UE) and User satisfaction (US) dimensions in the D\&M model. Arguments against dropping them are also available in the literature (see e.g. $[14,15,16]$ ). The retained ERP success dimensions in Gable and colleagues' model are System Quality (SQ), Information Quality (IQ), Individual Impact (II), and Organizational Impact (OI). Through literature reviews and case studies, Ifinedo [14, 15] proposed an extended ERP system success measurement model to include Workgroup Impact (WI) not included in the Gable et al. model. The author argues that any ERP success measurement model should include a dimension related to WI because ERP systems are often adopted to enhance efficient cross-functional operations $[2,9,18]$. Here, "workgroup" refers to the sub-units and/or functional departments of an organization. A version of the extended ERP success measurement model proposed by Ifinedo [14] is illustrated in Figure 2.

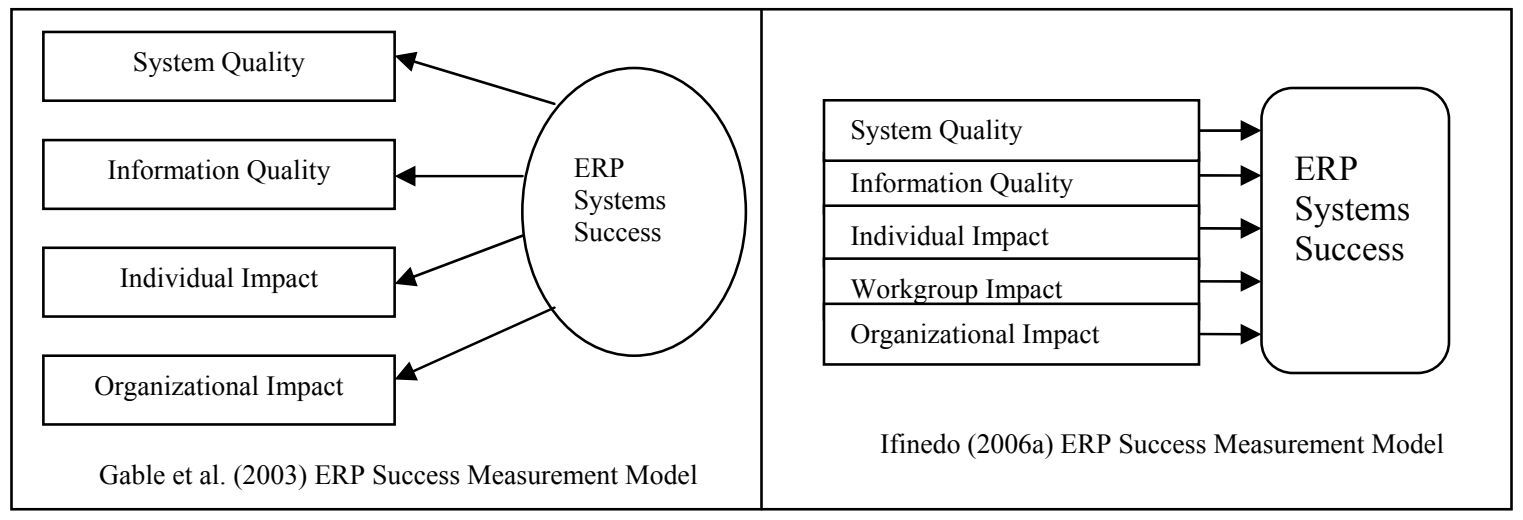

Figure 2. ERP Systems Success Measurement Models

\section{HYPOTHESES}

The hypothesized paths shown in Figure 3 are developed from the dimensions in Ifinedo's [14] to follow the direction of flow in the D\&M model. The statements of hypotheses and discussions are presented below.

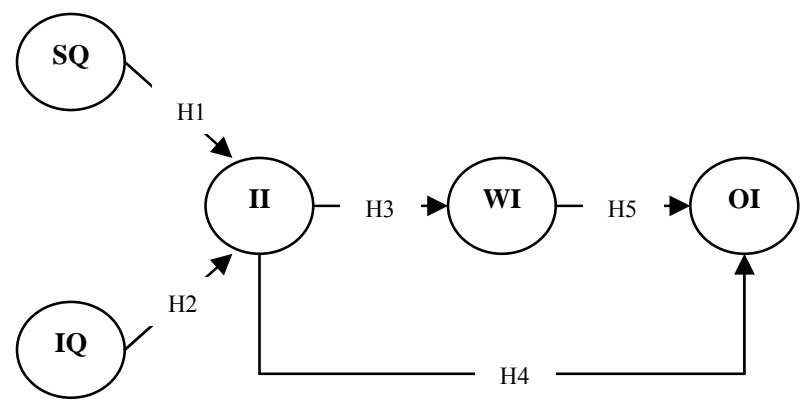

Figure 3. Relationships among Paths in the ERP Systems Success Model Tested in this Study

The study by Rai et al. [24] and Seddon and Kiew [25] showed a positive relationship between System Quality and "usefulness". Upon examining the measures used to measure this item in both studies, some salient similarities were noticed between their "usefulness" construct and the one used in this study for Individual Impact. In the context of ERP systems, using multiple regression analysis, Calisir and Calisir [6] report significant path coefficients perceived ease of use and perceived usefulness $(\beta=0.381)$ and between system capability and perceived usefulness $(\beta=0.354)$. Similarly, Seddon and Kiew [25] found that increases in Information Quality led to more "usefulness" of an IS as assessed from the perspective of the individual. Both in their empirical 
tests of the D\&M model and in the alternative IS success measurement model proposed by other researchers, including Rai et al. [24] found that Information Quality is positively related to "perceived usefulness". Indeed, prior literature (e.g. [19]) has also shown that increased Information Quality will lead to increased usefulness of an IS for the individual. It is therefore hypothesized that:

$\mathrm{H}_{1}$ : Increases in System Quality will cause increases in Individual Impact.

$\mathrm{H}_{2}$ : Increases in Information Quality will cause increases in Individual Impact.

Myers et al. [22] argue that the individuals in organizations belong to sub-units, and that when IS success evaluation issues incorporate or accommodate the analysis at the sub-unit level, useful insights might emerge [3, 4]. However, the search result for literature establishing relationships positive or otherwise - between Individual Impact and sub-unit or Workgroup Impact did not yield any success. Ceteris paribus, when the effect arising from the use of an IS is high for an individual, it is likely that the impact for the workgroup or sub-unit to which the individual belongs will also be high. Evidence in support for this viewpoint is partially provided by the direction of flow in the DeLone and McLean [10] IS success evaluation model as well as in the alternative IS success measurement model that Myers et al. [22] proposed. The flow also indicates that as the effects of an IS on the individual increase, so will the impact on the workgroups, and ultimately for the organization $[3,4,10,22]$. Based on this brief discussion the following set of hypotheses is formulated

$\mathrm{H}_{3}$ : Increases in Individual Impact will cause increases in Workgroup Impact.

$\mathrm{H}_{4}$ : Increases in Individual Impact will cause increases in Organizational Impact.

$\mathrm{H}_{5}$ : Increases in Workgroup Impact will cause increases in Organizational Impact.

\section{RESEARCH METHODOLOGY}

\section{Data Collection}

This study is conducted in Finland and Estonia - two small neighboring technologically advanced Northern European countries with a record of ERP adoption $[15,20]$. The responses used in this research were obtained from surveys of companies' directories (e.g., online database of Finnish companies: http://www.yritysopas.com/ and Estonian Chamber of Commerce and Industry Directory 2004: http://mail.koda.ee/ektk/koda eng) and contact persons in the two countries. 350 and 120 firms in Finland and Estonia were identified from those sources. The unit of analysis of this study was at the firm level. Firms were chosen by the researcher's ability to obtain contact addresses for individuals that could be described as "key informants" in the selected firms. Key informants are individuals with access to organizational information [15]. Respondents received a packet consisting of a cover letter, questionnaire, and a self-addressed, stamped envelope.

About $60 \%$ of the mailings to the participants included only one questionnaire; the rest (40\%) of the mailings had two questionnaires. It was decided that multiple respondents from one organization would enhance the validity of the study as a common source bias would be minimized. Subjects were encouraged to present views representative of their organization. To ensure data validity and reliability of the survey instrument, four knowledgeable individuals (i.e. two IS faculty, one ERP consultant and one ERP managerial level user) completed the 41-item questionnaire before our mailing it out, and their comments helped us improve its quality. The questionnaire used measures that have been validated in the literature (please see [14]). Respondents in the surveys indicated their degree of agreement with statements using a 7-point, Likert-type scale, where 1 $=$ strongly disagree and $7=$ strongly agree. To ensure each organizational stakeholder group presented a view representative of organization-wide perspectives, the questions in the questionnaire were posed appropriately (Please see the Appendix).

\section{The Sample}

The respective response rate, excluding the received questionnaires that were unusable, was 29 firms (8.5\%) for Finland, 15 firms (12.5\%) for Estonia, and $44(9.5 \%)$ combined for the two countries. The study received 62 individual responses: 39 from Finland and 23 from Estonia. It is worth mentioning that our data collection effort reflects the typically low responses that are commonly seen for IS studies in the region and for surveys targeting midlevel and senior employees in organizations (Ifinedo, 2006b). The data classified by occupation comprised 20 $(32.3 \%)$ IT professionals/managers and $42(67.7 \%)$ business managers. Their job titles included chief executive officer, chief information officer, chief accountant, IT manager, and finance manager. There 
were $35(56.5 \%)$ men and $27(43.5 \%)$ women in our sample. Of the respondents, $40 \%$ had college degrees, $20 \%$ had technical and other vocational education, and $43(69.3 \%)$ were between 31 and 50 years old. On average, they had nine (9) years of work experience in their respective organizations. Of the 62 respondents, $33.9 \%$ had SAP in their organizations, $14.5 \%$ had Movex, 9.6\% had Scala, $8.1 \%$ had Hansa, and the remaining $33.9 \%$ had other mid-market ERP products, including Concorde, Nova, etc. The annual turnover of the firms in the sample ranged from $€ 1$ million to a little over $€ 2$ billion, with $€ 19$ million as the median. The workforce ranged from 10 to 13, 000 employees, with a median of 120 employees. Responses were received from a wide range of industries including manufacturing, financial services, IT firms, pharmaceuticals, food processing, retail, and warehouse businesses. The sample classified by the size of workforce following guidelines provided by Laukkanen et al. [20] included 15 (24\%) small, 25 (40\%) medium-sized, and 22 (36\%) large firms.

\section{DATA ANALYSIS}

A structural equation modeling (SEM) technique is used to examine the relationships among the constructs. The PLS (Partial Least Squares) approach is preferred for its capability to accommodate smallsized samples [7]. PLS recognizes two components of a casual model: the measurement model and the structural model. The measurement model consists of relationships among the factors of interest (i.e., the observed variables) and the measures underlying each construct; it demonstrates the construct validity of the research instrument (i.e. how well the instrument measures what it purports to measure. In the structural model, this measure gives information as to how well the theoretical model predicts the hypothesized paths or relationships. PLS software provides the squared multiple correlations $\left(\mathrm{R}^{2}\right)$ for each endogenous construct in the model and the path coefficients. The $\mathrm{R}^{2}$ indicates the percentage of a construct's variance in the model while the path coefficients indicate the strengths of relationships between constructs [7].

\section{Assessing the Measurement and Structural Models}

The items loadings, composite reliabilities and the Cronbach alphas of the constructs are shown in the Appendix. The values obtained are adequate for this study. Figure 4 shows the path coefficients and the size of the $\mathrm{R}^{2}$ values. The test of significance of all the paths was done using the bootstrap resampling procedure with 200 resamples. The construct reliabilities, internal loading, and Cronbach alphas of the constructs measures are adequate for the study (please see the detail in the Appendix), and compare with recommended value of $0.7[7,23]$.

All the paths are significant at $\mathrm{p}=0.05$ level with exception of the path between Individual Impact and Organizational Impact. It can be seen that System Quality (SQ) and Information Quality (IQ) have strong relationships with the Individual Impact (II) dimension with path coefficients $(\beta)$ of 0.39 and 0.27 , respectively. The two constructs account for $31 \%$ in the variation of Individual Impact. There is also a strong relationship between Individual Impact and Workgroup Impact (WI) $(\beta=0.55)$. Similarly, II alongside the other dimensions account for $31 \%$ of the variation in the WI construct. Further, the relationship between Individual Impact and Organizational Impact is weak $(\beta=0.049)$. The Workgroup Impact dimension has a significant relationship with Organizational Impact $(\beta=0.56)$. Together, all the constructs explained $19 \%$ of the variance in the structural model.

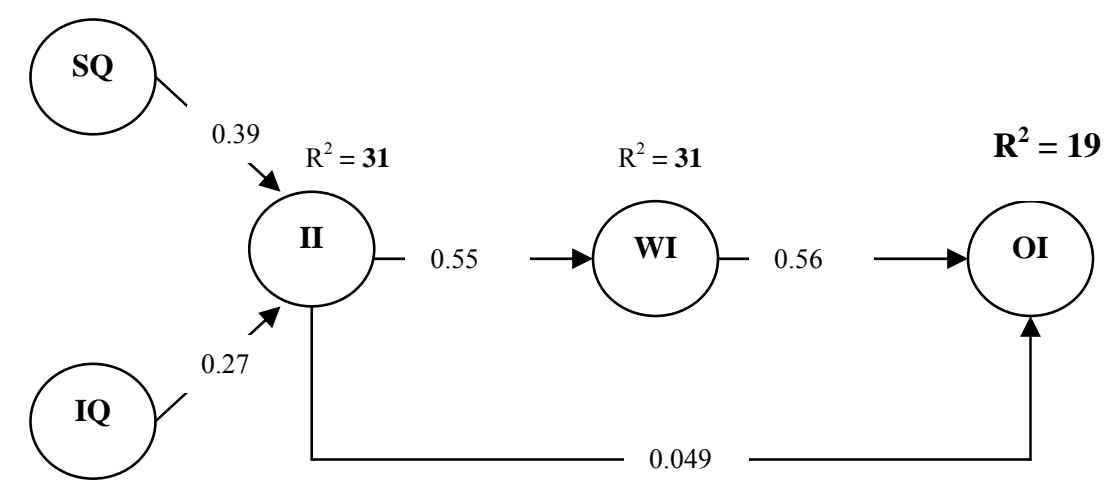

Figure 4. PLS Graph 3.0 Results of the Tested Paths in the Study 


\section{DISCUSSIONS AND CONCLUSION}

The objective of this research is to examine the interrelationships among the dimensions in an extended ERP systems success model. This study is among the first to discuss the relationships among the dimensions in any framework for assessing or measuring ERP systems success in organizations. The data analysis supported four of the five hypotheses formulated with the exception of $\mathrm{H} 4$, which examined the paths between Individual Impact and Organizational Impact. Plausible explanations for the lack of support for this hypothesis might be related to contextual influences, i.e. heterogeneity of the sample and instrument design. The other limitations in the study are highlighted as follows. The sample is not random, nor can personal bias be ruled out in instances where a single informant presented an average view for his or her respective organization. Although a sample size of 62 is statistically sufficient for analysis, a larger sample size might produce better insights. This study's finding reflects the viewpoint from firms (private organizations); as a result, it may not be possible to generalize to public sector organizations.

That said, the hypothesized paths among the dimensions of ERP success seem to have an adequate predictive power for the model. To that end, this study offers useful insights for both ERP practitioners and IS researchers with regard to the nature of the relationships among the dimensions of success for ERP systems. The study's data analysis suggests that System Quality, in the context of ERP systems, is positively related to Individual Impact. This information supports the widely tested paths between these two constructs for other IT systems [e.g., 24, 25], and it also supports the work by Calisir and Calisir [6] using ERP systems. Thus, this finding seems to be suggesting that such a relationship might hold for a wide range of IS. Similarly, the results show that a relationship exists between Information Quality and Individual Impact as other prior studies did [19, 24, 25].

It is somewhat surprising that the hypothesized path between Individual Impact and Organizational Impact was unsupported. This finding is at variance with the conceptualization of IS success evaluations in DeLone and McLean [10]. This finding permits us to argue that were the analysis of the data used in this study to be performed using the D\&M IS success model, it would have concluded that Individual Impact and Organizational Impact are unrelated, at least in the context of ERP systems. However, the inclusion of analysis at the sub-unit level facilitated a deeper understanding, which suggested that there is a direct pattern of flow from Individual Impact to Organizational Impact, through the Workgroup Impact. This study showed that positive relationships exist between the dimensions of Individual Impact and Workgroup Impact and Organizational Impact when assessed in that order. To some extent, this information lends credence to the notion that the impact of IT might follow such a flow (or order). Other researchers have implied this direction of flow (e.g. $[3,22])$. ERP practitioners also benefits from the empiric information suggesting that the organizational impacts of acquired ERP systems increases with corresponding increases of the software's impacts on the individual and the various sub-units within the organization. Future ERP researchers may want ask why the direct link between the Individual Impact and Organizational Impact is unsubstantiated while its pertinence holds through the Workgroup Impact. Lastly another fruitful avenue for future study would be to establish and confirm the nature of this purported flow in other enterprise systems, including ERP and CRM (Customer Relationship Management) in other settings.

\section{REFERENCES}

1. Akkermans, H. and van Helden, K. (2002). Vicious and virtuous cycles in ERP implementation: a case study of interrelations between critical success factors. European Journal of Information Systems, 11(1), 35-46.

2. AMR Research (2005). \$17 billion expected future growth in enterprise applications market. Available:

http://www.amrresearch.com/Content/View.asp? pmillid=18789.

3. Bakos, J. Y. (1987). Dependent variables for the study of firm and industry-level impacts of information technology. Proceedings of 8th. ICIS, Pittsburgh, PA.

4. Barua, A., Kriebel, C. and Mukhopadhyay, T. (1995). Information technologies and business value: an analytic and empirical investigation. Information Systems Research, 6 (1), 3-23.

5. Bingi, P., Sharma, M. and Godla, J. (1999). Critical issues affecting an ERP implementation. Information Systems Management, 16(3), 7-14.

6. Calisir, F. and Calisir, F. (2004). The relation of interface usability characteristics, perceived usefulness, and perceived ease of use to end-user satisfaction with enterprise resources planning 
(ERP) systems. Computers in Human Behavior, 20(4), 505-515.

7. Chin, W. (1998). Issues and opinion on structural equation modeling. MIS Quarterly, 22(1), viixvi.

8. Davenport, T. (1998). Putting the enterprise into the enterprise system. Harvard Business Review, 76(4), 121-131.

9. Davenport, T. (2000). Mission critical. Boston, MA: .Harvard Business School Press.

10. DeLone, W.H. and McLean, E.R. (1992). Information systems success: the quest for the dependable variable. Information Systems Research, 3(1), 60-95.

11. Esteves, J. and Pastor. J. (2001). Enterprise resource planning systems research: an annotated bibliography. Communications of the AIS, 7(8), $1-52$.

12. Gable, G. G., Sedera, D. and Chan T. (2003). Enterprise systems success: a measurement model. Proceedings International Conference on Information Systems (ICIS), Seattle, WA.

13. Hong, K. and Kim, Y. (2002). The critical success factors for ERP implementation: an organizational fit perspective. Information and Management, 40(1), 25-40.

14. Ifinedo, P. (2006a). Extending the Gable et al. enterprise systems success measurement model: a preliminary study. Journal of Information Technology Management, 17(1), 14-33.

15. Ifinedo, P. (2006b). Enterprise resource planning systems success assessment: an integrative framework. PhD Thesis, Dept. of Computer Science and Information Systems, University of Jyväskylä, Finland.

16. Iivari, J. (2005). An empirical test of the DeLone-McLean model of information system success. The DATA BASE for Advances in Information Systems, 36(2), 8-27.

17. Keen, P. (1980). MIS Research: reference disciplines and a cumulative tradition.
Proceedings of the 1st. ICIS, Philadelphia, PA.

18. Klaus, H., Rosemann, M. and Gable, G.G. (2000). What is ERP? Information Systems Frontier, 2(2), 141-162.

19. Kraemer, K. L., Danzinger, J. N., Dunkle, D. E. and King, J. L. (1993). The usefulness of computer-based information to public managers. MIS Quarterly, 17(2), 129-148.

20. Laukkanen, S., Sarpola, S. and Hallikainen, P. (2005). ERP system adoption - Does the size matter? Proceedings of the 38th. Hawaii International Conference on System Sciences, Hawaii.

21. Martin, M. (1998). Enterprise resource planning. Fortune, 137(2), 149-151.

22. Myers, B. L., Kappelman, L. A., and Prybutok, V. R. (1996). A case for including work group productivity measures in a comprehensive IS assessment model. Proceedings of the 27th. Decision Sciences Institute, Orlando, FL.

23. Nunnally, J. C. (1978). Psychometric theory. New York, NY: McGraw-Hill,

24. Rai, A., Lang, S. S., and Welker, R. B (2002). Assessing the validity of IS Models: an empirical test and theoretical analysis. Information Systems Research, 13(1), 50-69.

25. Seddon, P. B. and Kiew, M-Y. (1994). A partial test and development of the DeLone and McLean model of IS success. Proceedings of the International Conference on Information Systems (ICIS), Vancouver, Canada.

26. Sedera, D. and Gable, G. (2004). A factor and structure equation analysis of the enterprise systems success measurement model. Proceedings of the 25th. International Conference on Information Systems (ICIS), Washington, D. C.

27. Yu, C-S. (2005). Causes influencing the effectiveness of the post-implementation ERP system. Industrial Management \& Data Systems, 105(1),
115-132. 
Appendix 1: Measures, internal loadings, Cronbach alphas, and construct reliability

\begin{tabular}{|c|c|c|c|c|}
\hline No./Dimension & Measures in the questionnaire & $\begin{array}{l}\text { Item } \\
\text { loading }\end{array}$ & $\begin{array}{l}\text { Cronbach } \\
\text { alpha }\end{array}$ & $\begin{array}{l}\text { Construct } \\
\text { reliability }\end{array}$ \\
\hline 1 & Our ERP has accurate data & 0.3103 & \multirow{11}{*}{0.852} & \multirow{11}{*}{0.706} \\
\hline 2 & Our ERP is flexible & 0.2535 & & \\
\hline 3 & Our ERP is easy to use & 0.4949 & & \\
\hline 4 & Our ERP is easy to learn & 0.7737 & & \\
\hline 5 & Our ERP is reliable & 0.3361 & & \\
\hline SQ & Our ERP allows data integration & 0.3673 & & \\
\hline 7 & Our ERP allows for customization & 0.1626 & & \\
\hline 8 & Our ERP is efficient & 0.4852 & & \\
\hline 9 & Our ERP has good features & 0.5859 & & \\
\hline 10 & $\begin{array}{l}\text { Our ERP allows for integration with other IT } \\
\text { systems }\end{array}$ & 0.2377 & & \\
\hline 11 & Our ERP meets users' requirements & 0.5787 & & \\
\hline 12 & Our ERP database contents is up-to-date & 0.4544 & \multirow{8}{*}{0.822} & \multirow{8}{*}{0.632} \\
\hline 13 & Our ERP has timely information & 0.5691 & & \\
\hline 14 & $\begin{array}{l}\text { The information on our ERP is } \\
\text { understandable }\end{array}$ & 0.3361 & & \\
\hline IQ & The information on our ERP is important & 0.7660 & & \\
\hline 16 & The information on our ERP is brief & -0.0254 & & \\
\hline 17 & The information on our ERP is relevant & 0.2630 & & \\
\hline 18 & The information on our ERP is usable & 0.6783 & & \\
\hline 19 & The information on our ERP is available & 0.6988 & & \\
\hline 20 & Our ERP enhances individual creativity & 0.4345 & \multirow{6}{*}{0.769} & \multirow{6}{*}{0.685} \\
\hline 21 & $\begin{array}{l}\text { Our ERP enhances organizational learning } \\
\text { and recall for individual worker }\end{array}$ & 0.4713 & & \\
\hline 22 & Our ERP improves individual productivity & 0.2951 & & \\
\hline 23 & Our ERP is beneficial for individual's tasks & 0.6152 & & \\
\hline 24 & $\begin{array}{l}\text { Our ERP enhances higher-quality of } \\
\text { decision making }\end{array}$ & 0.7907 & & \\
\hline 25 & $\begin{array}{l}\text { Our ERP saves time for individual tasks } \\
\text { and duties }\end{array}$ & 0.4523 & & \\
\hline 26 & $\begin{array}{l}\text { Our ERP helps to improve workers' } \\
\text { participation in the organization }\end{array}$ & 0.5257 & \multirow{7}{*}{0.810} & \multirow{7}{*}{0.748} \\
\hline 27 & $\begin{array}{l}\text { Our ERP improves organizational-wide } \\
\text { communication }\end{array}$ & 0.6787 & & \\
\hline 28 & $\begin{array}{l}\text { Our ERP improves inter-departmental } \\
\text { coordination }\end{array}$ & 0.6672 & & \\
\hline WI & Our ERP creates a sense of responsibility & 0.3726 & & \\
\hline 30 & $\begin{array}{l}\text { Our ERP improves the efficiency of } \\
\text { sub-units in the organization }\end{array}$ & 0.5556 & & \\
\hline 31 & Our ERP improves work-groups productivity & 0.4836 & & \\
\hline 32 & Our ERP enhances solution effectiveness & 0.5171 & & \\
\hline 33 & Our ERP reduces organizational costs & 0.4659 & \multirow{8}{*}{0.867} & \multirow{8}{*}{0.709} \\
\hline 34 & Our ERP improves overall productivity & 0.6840 & & \\
\hline 35 & Our ERP enables e-business / e-commerce & 0.1245 & & \\
\hline 36 & Our ERP provides us with competitive advantage & 0.6037 & & \\
\hline OI & Our ERP increases customer service/ satisfaction & 0.4449 & & \\
\hline 39 & Our ERP facilitates business process change & 0.2329 & & \\
\hline 40 & Our ERP supports decision making & 0.6095 & & \\
\hline 41 & $\begin{array}{l}\text { Our ERP allows for better use of organizational } \\
\text { data resource }\end{array}$ & 0.6324 & & \\
\hline
\end{tabular}

Note: "Our ERP" refers to the type(s) of ERP system in use in the participating firms. 